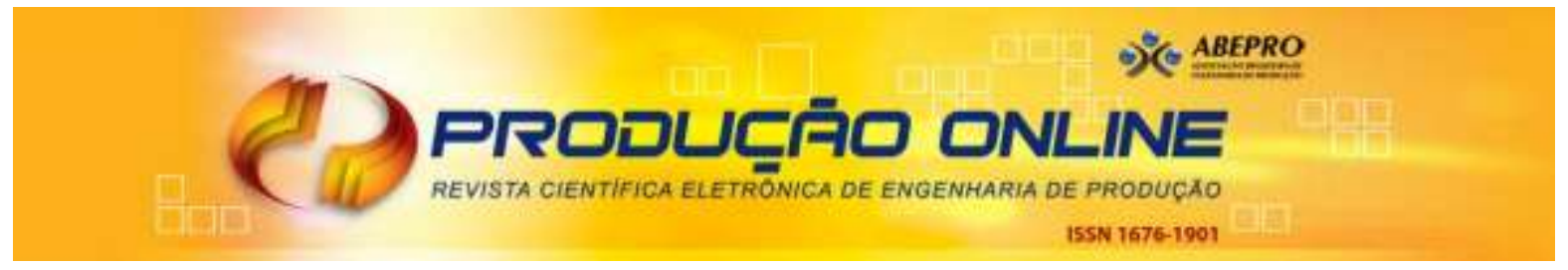

\title{
DESDOBRAMENTO DA FLEXIBILIDADE DA MANUFATURA EM FUNÇÃO DA DEMANDA DO CONSUMIDOR E DA ESTRATÉGIA DA EMPRESA ${ }^{1}$
}

\section{THE DEPLOYMENT OF MANUFACTURING FLEXIBILITY AS A FUNCTION OF COMPANY STRATEGY}

\author{
Carla Cristina Amódio Estorilio*E-mail: amodio@utfpr.edu.br \\ Clever Guimarães Esturilho** E-mail: clever.esturilho@fae.edu.br \\ *Universidade Tecnológica do Paraná (UTFPR), Curitiba, PR \\ ** Mondelēz Brasil (MDLZ), Curitiba, PR
}

\begin{abstract}
Resumo: A flexibilidade é uma das características estratégicas nas indústrias de manufatura. Entretanto, faltam recursos capazes de orientar quanto ao nível de flexibilidade ideal para cada caso, atrelado às formas de operacionalização, comprometendo o desempenho do processo. Esse artigo apresenta um método para orientar na escolha dos recursos provedores da flexibilidade, considerando a demanda do consumidor e os objetivos estratégicos da empresa. Primeiramente, é apresentada uma revisão sobre flexibilidade, classificando-a em: habilidades, dimensões, elementos e recursos provedores da flexibilidade. Baseada nessa taxonomia e com o QFD (Desdobramento da Função Qualidade), um método é desenvolvido, apresentando uma correlação entre esses quatro níveis, partindo da demanda do consumidor e da estratégia da empresa. O método foi testado em uma empresa automotiva, o qual permitiu adequar a estratégia da empresa e o mercado consumidor com o nível de flexibilidade praticado. Constatou-se que o índice de automação comprometia o mix de produtos, o qual poderia melhorar com a simplificação das tarefas ou com mais funcionários experientes e polivalentes. Entre os diferenciais desse artigo está o fato deste método considerar o nível estratégico da empresa e desdobrar quatro níveis da flexibilidade.
\end{abstract}

Palavras-chave: Flexibilidade. Manufatura. QFD. Automação. Automotiva.

Abstract: The flexibility is one of the priorities in manufacturing companies. However, the lack of guidelines for carrying out a critical analysis of the use of resources in manufacturing industry leads to a loss of process performance. This article describes a method to help companies identify the resources needed to provide manufacturing flexibility and meet the demands of their consumers while complying with company strategy. The literature related to flexibility is reviewed and a classification based on four levels is proposed: abilities, dimensions, elements and resources that provide flexibility. Based on this taxonomy and using the principles of QFD (Quality Function Deployment), a method is proposed that shows the correlation between these four levels, starting with customer demand and company strategy. The method was tested in an automobile manufacturing company, showing the applicability of the method. It highlighted the high degree of automation, which's had serious problems related to restrictions on product mix. It can be inferred that this problem could be minimized by simplifying the tasks involved in the manufacture of car and by hiring more experienced, multi-skilled workers. The proposed method is different from those founded in the literature review because it deploys two levels more of flexibility, considering the QFD structure, and addresses strategic company issues.

Keywords: Flexibility. Manufacturing. QFD. Automation. Automotive.

Revista Produção Online, Florianópolis, SC, v.13, n. 3, p. 945-973, jul./set. 2013. 


\section{INTRODUÇÃO}

Em função da competitividade, as prioridades das empresas de manufatura são inovação, qualidade, tempo de desenvolvimento de produtos, preço e flexibilidade. Entre essas, a flexibilidade tem ganhado importância, sendo apontada como uma característica estratégica para essas indústrias, com forte correlação com as demais características (Oke, 2005).

Marilyn e Olga (2011) defendem a flexibilidade como forma de criar oportunidades, ao invés de seu uso reativo em resposta às incertezas do mercado. Para isso, sugerem a integração do posicionamento competitivo da empresa com recursos operacionais, gerando uma visão mais ampla da flexibilidade quanto a criação de uma vantagem competitiva. Boyle e Scherrer-Rathje (2009) também defendem essa idéia. Eles constataram que incorporar a flexibilidade da fabricação na estratégia da manufatura é uma das práticas mais relevantes para melhorar a flexibilidade, em consonância com os objetivos da fabricação e da organização, conforme opinião de 168 gestores de produção pesquisados.

Baseado nessas constatações, diversos recursos têm sido empregados para promover flexibilidade nos processos de fabricação das indústrias de manufatura. Entre eles, podem-se citar os seguintes: automação flexível, capacitação polivalente da mão de obra, novas abordagens sobre estoques, entre outros.

Cousens et al. (2009) desenvolveram e testaram um procedimento para que as organizações estabelecessem uma capacidade competitiva para a fabricação de forma flexível. Eles propuseram um quadro com recursos operacionais para atuar em duas dimensões da flexibilidade: no mix (tipos de produtos) e no volume de produtos.

Relacionado ao mix e volume de produtos, Conceição et al. (2009) discutem o problema de quem fabrica variedade de produtos com alto valor agregado e curto ciclo de vida, com instabilidade da demanda, exigindo flexibilidade da produção. Para minimizar esse problema eles sugeriram a aplicação de um método para reduzir o tempo de preparação de máquinas e troca de ferramentas, o qual apresentou ganhos de produtividade e financeiros. 
Rodrigues e Gomez (2008) também focam na questão do tempo de troca de ferramenta. Eles abordam o problema de escalonamento na linha de produção, aplicado a um Sistema de Manufatura Flexível, onde um conjunto de produtos é processado por um conjunto de máquinas, tendo cada produto uma rota diferente no sistema fabril. A meta nesse caso é a minimização do tempo total de produção. Para contribuir na resolução desse conflito, os autores consideram as restrições de datas de entrega, dos turnos de produção e de trocas de ferramentas. Considerando a restrição de ferramentas, eles sugerem agrupar as partes dos produtos considerando as similares, possibilitando o processamento de lotes de partes.

Nakamoto et al. (2009) identificam uma restrição do Sistema Flexível de Manufatura (FMS), relacionada à questão deste executar múltiplos processos simultaneamente, utilizando recursos limitados. Em função desse fato, o sistema poderia gerar um autotravamento. Para evitar esse problema, os autores propõe uma forma de automatizar a estratégia de controle para a utilização de recursos e de regras para um FMS.

Enfim, vários autores identificam problemas e restrições em sistemas de manufatura que demandam flexibilidade e até sugerem recursos para resolver tais problemas. Entretanto, não se constata estudos que apresentem uma análise sistêmica da situação individual de uma empresa ou algum método que possa auxiliar nessa tarefa, visando identificar o nível de automação ideal para a flexibilidade demandada, indicando os recursos para promover tal flexibilidade. Afinal, conforme Koste e Malhotra (2000), enquanto os benefícios da flexibilidade parecem claros, o conceito e a operacionalização da flexibilidade ainda não são bem compreendidos. Perguntas do tipo: "O que é flexibilidade?"; "Quando uma empresa deve implantá-la?"; "Em que nível deve implantá-la?" e "Como pode ser implantada?", ainda são questões sem respostas. As empresas deveriam saber quais tipos e características da flexibilidade são benéficos para a sua organização específica, a fim de obter uma vantagem competitiva focada.

Entre os estudos que buscaram um enfoque mais sistêmico e orientativo para aqueles que precisam de flexibilidade em seus processos produtivos estão os seguintes: Olhager e West (2002), os quais utilizaram duas casas do QFD 
(Desdobramento da Função Qualidade-Quality Function Deployment) para desdobrar os requisitos do mercado em características dos processos de manufatura em termos de flexibilidade. A entrada desta aplicação são as "habilidades", referentes à diversidade, inovação, segmentação de mercado, estratégia de produto, entre outros, as quais são desdobradas em "características da flexibilidade", referentes à flexibilidade de volume, de mix, de novos produtos e de entrega. Posteriormente, desdobram essas características em "recursos provedores", que fornecem detalhes de máquinas e de pessoas para operacionalizar a flexibilidade na manufatura. Como resultado, o método apresenta as principais metas, incluindo métricas para controlar o planejamento para a obtenção da flexibilidade desejada. Entretanto, apesar da proposta auxiliar no desdobramento da flexibilidade, ela não considera todos os níveis envolvidos na flexibilidade. Segundo Kara e Kayis (2004), a flexibilidade poderia ser desdobrada em até quatro níveis, com forte correlação entre eles. São eles: as habilidades, as dimensões, os elementos e os recursos provedores da flexibilidade. Entretanto, os autores não apresentam um método que auxilie no planejamento de recursos geradores da flexibilidade.

Sendo assim, o objetivo desse trabalho é apresentar um método para orientar na escolha dos recursos provedores da flexibilidade, considerando a demanda do consumidor e os objetivos estratégicos da empresa. Para isso, apresenta revisões sobre o tema "flexibilidade", incluindo a revisão de estratégias e métodos sugeridos para a sua implantação. Baseado na revisão e em alguns desses métodos, um novo método é criado e testado em campo industrial, cujos resultados são relatados no final desse trabalho.

\section{FLEXIBILIDADE EM MANUFATURA}

Segundo Slack (1987), obter flexibilidade em um processo significa "prover recursos que possam ser modificados rapidamente de forma a criar uma gama de produtos". Yazici (2005) define flexibilidade olhando a interface empresa-mercado, 
ou seja, a "flexibilidade é a habilidade de um sistema de manufatura em lidar com as incertezas, acomodando flutuações de fornecedores e consumidores".

Nas pesquisas sobre flexibilidade em manufatura constata-se a utilização dos mais diversos termos para tratar dos mesmos conceitos e, em outros momentos, um termo apresenta diferentes significados (Browne et al., 1984; Slack, 1983, 1987; Hyun e Ahn, 1992; Suarez et al., 1996; Zhang et al., 2003; Koste et al., 2004). A grande variedade de termos na literatura deve-se à complexidade do conceito "flexibilidade" e às diferentes perspectivas e níveis de detalhamento analisados. Em função dessa diversidade e complexidade, uma breve revisão é apresentada, com o objetivo de delimitar uma classificação para a flexibilidade que a torne mais compreensível.

\subsection{Níveis de flexibilidade}

Kara e Kayis (2004) salientam a importância de uma estratégia suportada pela flexibilidade de manufatura, na qual as empresas mais competitivas são aquelas capazes de responder de forma rápida e eficiente. Esse estudo explora a relação existente entre habilidades capazes de atender aos anseios do mercado em termos de flexibilidade e as dimensões, elementos e recursos utilizados para tal. Nesse sentido, os autores desdobram a flexibilidade em quatro níveis (habilidades, dimensões, elementos e recursos), sugerindo que existe uma forte correlação entre eles.

Olhager e West (2002) sugerem algumas habilidades com foco no mercado consumidor, tais como: produtividade, disponibilidade, confiabilidade de entrega, preço, qualidade, lucratividade, inovação tecnológica e customização.

Como dimensões da flexibilidade, podem-se citar a flexibilidade de máquinas, de rotas, de intercambiabilidade de produtos, de volume de produção, entre outras. Esse estudo explora quatro dimensões da flexibilidade, sendo essas denominadas de "flexibilidade de volume, de mix, de novos produtos e de entrega". Koste e Malhotra (2000) sugerem outras duas dimensões da flexibilidade; a "flexibilidade de máquina e de mão de obra". Entretanto, essas são abordadas nesse trabalho como 
recursos provedores da flexibilidade. Afinal, a flexibilidade de máquina e de mão de obra, diferente da flexibilidade de volume, mix ou entrega, não são características desejadas pelas organizações, mas sim, recursos necessários para proporcionar flexibilidade de mix ou volume.

A flexibilidade de volume representa a capacidade de adaptação do sistema de produção à variação quantitativa da demanda do mercado. Ela tem como objetivo manter constante os custos variáveis de produção, sem afetar os custos fixos e outros fatores de desempenho tais como qualidade ou prazo de entrega do produto.

A flexibilidade de mix representa a variedade e a heterogeneidade de modelos que podem ser produzidos, sem incorrer em perdas de desempenho em termos de tempo e custos para preparar para a mudança de modelos e escalonamento da linha de produção (Koste e Malhotra, 1999).

A flexibilidade de novos produtos representa a quantidade e a variedade de produtos que podem ser introduzidos em uma linha de produção, sem desencadear penalidades de transição ou perdas de desempenho. As penalidades de transição usuais são o tempo e o custo de desenvolvimento ou de adaptação da linha (Koste e Malhotra, 1999).

A flexibilidade de entrega é dependente da capacidade da organização em gerenciar as consequências das variações externas e internas à empresa, tais como: prazo de fornecedores; greves; trâmite de alfândega; crescimento econômico; entre outros.

Quanto aos elementos da flexibilidade, existem muitos na literatura, com uma base comum compartilhada (Beamon, 1999; Bordoloi et al., 1999; Browne et al., 1984; D' Souza e Williams, 2000; Narain et al., 2000; Sethi e Sethi, 1990; Upton, 1994). Além desses autores, Koste e Malhotra (2000) indicam que o domínio de qualquer dimensão da flexibilidade pode ser avaliado através de quatro elementos: variedade, heterogeneidade, mobilidade e uniformidade.

A "variedade" representa o número de opções de produtos e modelos que o sistema pode atingir. A "heterogeneidade" significa o grau de diferença entre os produtos. De uma forma geral, uma grande heterogeneidade entre opções exige um alto grau de adaptação do sistema produtivo, ou seja, demanda um sistema 
altamente flexível. O elemento "mobilidade" representa a facilidade com o qual um sistema move-se de um estado a outro, correspondendo ao conceito de "facilidade de movimento" proposto por Slack (1983). Por exemplo, se a empresa fabrica veículos utilitários e altera as configurações para fabricar veículos de passeio, ela passou para um estado diferente do anterior. Slack (1983) sugere o uso das variáveis "tempo" e "custo" para avaliar esse elemento, em função da relação recíproca entre elas, evitando desencadear erros de avaliação. Um sistema com mais mobilidade que outro pode incorrer em custos extras, decorrentes do curto tempo de transição entre estados diferentes. O elemento "uniformidade" representa a estabilidade de desempenho de um sistema, apesar das mudanças necessárias. Essa estabilidade é medida através de indicadores, os quais estão relacionados com a produtividade, eficiência, qualidade, tempo, custo de processo, custo de produto e outros.

Em relação ao quarto nível de desdobramento da flexibilidade, relacionado aos recursos provedores, ele envolve recursos humanos e tecnológicos. Esse trabalho aborda quatro tipos de recursos provedores da flexibilidade. São eles: flexibilidade de máquina, de mão de obra, de rota e de gestão. Os quatro estão descritos a seguir, incluindo alguns exemplos:

- Flexibilidade de máquina: Relativa ao número e à variedade de atividades que uma máquina ou equipamento pode executar sem incorrer em perdas significativas de desempenho, cuja característica está associada à automação. Alguns dos recursos utilizados são os seguintes: FMS (sistemas flexíveis de manufatura), robôs, máquinas CNC (controle numérico computacional), controladores lógicos programáveis, sistemas inteligentes de manipulação, transportadores terrestres e aéreos (Koste e Malhotra, 2000);

- Flexibilidade de mão de obra: Relacionada ao número e variedade de tarefas que um trabalhador pode executar sem acarretar em perdas significativas de desempenho. Nesse trabalho adota-se o modelo proposto por karuppan (2004), para a análise da flexibilidade de mão de obra, o qual utiliza três categorias: fatores individuais (tempo de função e personalidade); fatores organizacionais 
(foco em qualidade, flexibilidade, custo e tempo) e fatores do trabalho (responsabilidade compartilhada, automação e complexidade do trabalho);

- Flexibilidade de rota: Definida como "a facilidade com a qual os produtos podem ser fabricados, alternando a utilização de máquinas ou equipamentos" (Schewchuk e Moodie, 1998). A flexibilidade de rota tem relação com o fluxo de produtos no processo de fabricação;

- Flexibilidade de gestão: Envolve métodos, ferramentas e recursos, cujo suporte se baseia em estratégias de ação. Esses recursos estão relacionados ao modo de pensar, organizar e estruturar o processo produtivo, com impacto direto e indireto sobre a flexibilidade da manufatura.

O Quadro 1 apresenta uma síntese das dimensões da flexibilidade, conforme os autores previamente citados, apresentando-os em quatro níveis de desdobramentos.

Quadro 1 - Taxonomia das relações da Flexibilidade encontradas na literatura

(continua)

\begin{tabular}{|c|c|c|c|c|}
\hline Habilidades & Dimensões & Elementos & \multicolumn{2}{|r|}{ Recursos provedores } \\
\hline $\begin{array}{l}\text {-Confiabilidade de } \\
\text { entrega } \\
\text {-Customização } \\
\text {-Disponibilidade } \\
\text {-Inovação } \\
\text { tecnológica }\end{array}$ & $\begin{array}{l}\text {-Flexibilidade de } \\
\text { mix } \\
\text {-Flexibilidade de } \\
\text { volume } \\
\text {-Flexibilidade de } \\
\text { entrega }\end{array}$ & $\begin{array}{l}\text {-Variedade } \\
\text {-Heterogeneidade } \\
\text {-Mobilidade } \\
\text {-Uniformidade }\end{array}$ & 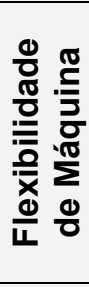 & $\begin{array}{l}\text {-Robôs } \\
\text {-CLPs (Controladores } \\
\text { Lógicos Programáveis) } \\
\text {-Transportadores } \\
\text { Dedicados } \\
\text {-Transportadores não } \\
\text { dedicados }\end{array}$ \\
\hline $\begin{array}{l}\text {-Lucratividade } \\
\text {-Preço baixo } \\
\text {-Produtividade } \\
\text {-Qualidade } \\
\text {-Velocidade de } \\
\text { entrega }\end{array}$ & $\begin{array}{l}\text {-Flexibilidade de } \\
\text { novos produtos }\end{array}$ & & $\begin{array}{l}\frac{0}{0} \\
\frac{0}{0} \\
\frac{0}{0} \\
\frac{\pi}{0} \\
\frac{0}{0} \\
\frac{0}{0} \\
\frac{0}{x} \\
\frac{0}{4}\end{array}$ & $\begin{array}{l}\text {-Tempo de Função } \\
\text {-Personalidade } \\
\text {-Foco em qualidade } \\
\text {-Foco em Flexibilidade } \\
\text { (poli-valência) } \\
\text {-Foco em custo } \\
\text {-Foco em tempo } \\
\text {-Responsabilidade } \\
\text { Compartilhada } \\
\text {-Grau de Automação } \\
\text {-Complexidade do } \\
\text { Trabalho }\end{array}$ \\
\hline
\end{tabular}

Revista Produção Online, Florianópolis, SC, v.13, n. 3, p. 945-973, jul./set. 2013. 
Quadro 1 - Taxonomia das relações da Flexibilidade encontradas na literatura

(conclusão)

\begin{tabular}{|c|c|c|c|c|}
\hline Habilidades & Dimensões & Elementos & \multicolumn{2}{|r|}{ Recursos provedores } \\
\hline & & & 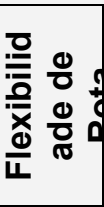 & $\begin{array}{l}\text {-Arranjo físico posicional } \\
\text {-Arranjo físico por } \\
\text { processo } \\
\text {-Arranjo físico celular } \\
\text {-Arranjo físico por produto }\end{array}$ \\
\hline & & & 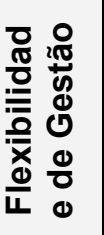 & $\begin{array}{l}\text {-Integração de processos } \\
\text {-Produção enxuta } \\
\text {-Produção em massa } \\
\text {-Utilização de } \\
\text { trabalhadores polivalentes } \\
\text {-outros. }\end{array}$ \\
\hline
\end{tabular}

Visando compreender como essa informação foi utilizada e como esse trabalho foi desenvolvido, visando atingir o objetivo proposto inicialmente, uma explanação sobre a metodologia da pesquisa será detalhada.

\section{METOdOLOGIA DA PESQUisA E ESTRUTURAÇÃo DO MÉTOdO PROPOSTO}

Como pôde ser visto, primeiramente foram revisados temas relacionados com a flexibilidade na manufatura, incluindo revisões de métodos e propostas para auxiliar na implantação da flexibilidade. Após uma análise da literatura, definiu-se que o método proposto seria composto por quatro matrizes de relacionamento e que estas seriam desdobradas da seguinte forma, aproveitando todo o material revisado: habilidades, dimensões, elementos e recursos provedores. Ou seja, o trabalho parte da proposta de Olhager e West (2002), a qual é complementada com os níveis da flexibilidade identificados por Kara e Kayis (2004), além de considerar outros autores revisados. O método utiliza o QFD das quatro fases, desenvolvido por Akao (1990), visando suportar e explorar a relação existente entre os quatro níveis da flexibilidade. O método proposto, denominado por "Desdobramento Estratégico da Flexibilidade - DEF", promove o desdobramento da seguinte forma: ele inicia com questões estratégicas e identifica as relações existentes com as "habilidades". As "habilidades" são relacionadas com as "dimensões da flexibilidade". As "dimensões" são relacionadas com os "elementos" e estes com os "recursos provedores da flexibilidade". Desta forma, o método permite detalhar os recursos provedores da 
flexibilidade para operacionalizar a demanda da empresa. A estrutura do "Método DEF" é apresentada na Figura 1.

Figura 1 - Desdobramento estratégico da Flexibilidade.

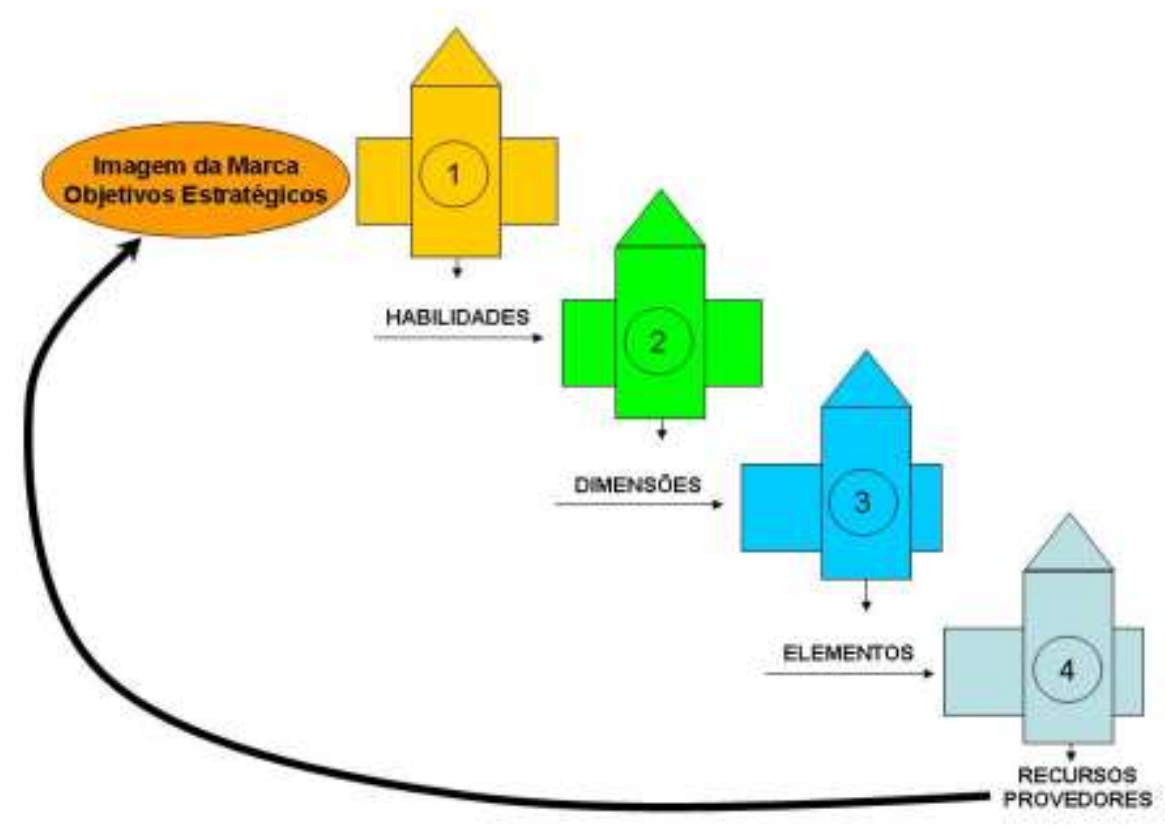

Para a aplicação do método sugere-se iniciar com a identificação das demandas do mercado, a fim de atingir os objetivos estratégicos da empresa através da satisfação dos clientes. A identificação dessas demandas é realizada a partir de dados coletados pelos setores de marketing e engenharia e são denominadas de Qualidades Exigidas (QE).

Após a identificação das demandas, deve-se compor um questionário, onde cada demanda deve ser pontuada quanto ao nível de importância para a empresa, considerando seus objetivos estratégicos. Os respondentes podem ser aqueles que tenham conhecimento do mercado, além de terem o domínio da política e cultura da empresa. Os pesos podem variar de 1 a 5 , sendo 1 para importância mínima e 5 para importância máxima. Dessa forma, identifica-se a importância atribuída para cada Qualidade Exigida. O peso representativo deve ser um número inteiro, resultante da média aritmética simples dos valores atribuídos por todos os respondentes. Por exemplo; se para o requisito "preço", o nível de importância 
atribuído de zero a cinco, entre dez respondentes, foi de 5 para oito respondentes, 3 para um respondente e 2 para o último respondente, compreende-se que o nível quatro de importância represente esse grupo, considerando o valor inteiro da média aritmética que resultou em 4,5. Portanto, o requisito "preço" teria como peso o nível 4 de importância.

Detalhando a primeira casa, a matriz é estruturada da seguinte forma: as Qualidades Exigidas, com seus níveis de importância, são os dados de entrada. Posteriormente, as Qualidades Exigidas são relacionadas com as $\underline{\text { Habilidades em }}$ manufatura. Essa primeira casa resulta em quais habilidades tem mais impacto na percepção do cliente sobre a empresa, considerando as habilidades descritas na revisão da literatura: confiabilidade de entrega, customização, disponibilidade, inovação tecnológica, lucratividade, preço baixo, produtividade, qualidade ou velocidade de entrega. A Figura 2 apresenta a construção da primeira casa chamada de Matriz de Habilidades.

Figura 2 - Esquema Básico da $1^{\text {a }}$ Casa (Matriz de Habilidades).

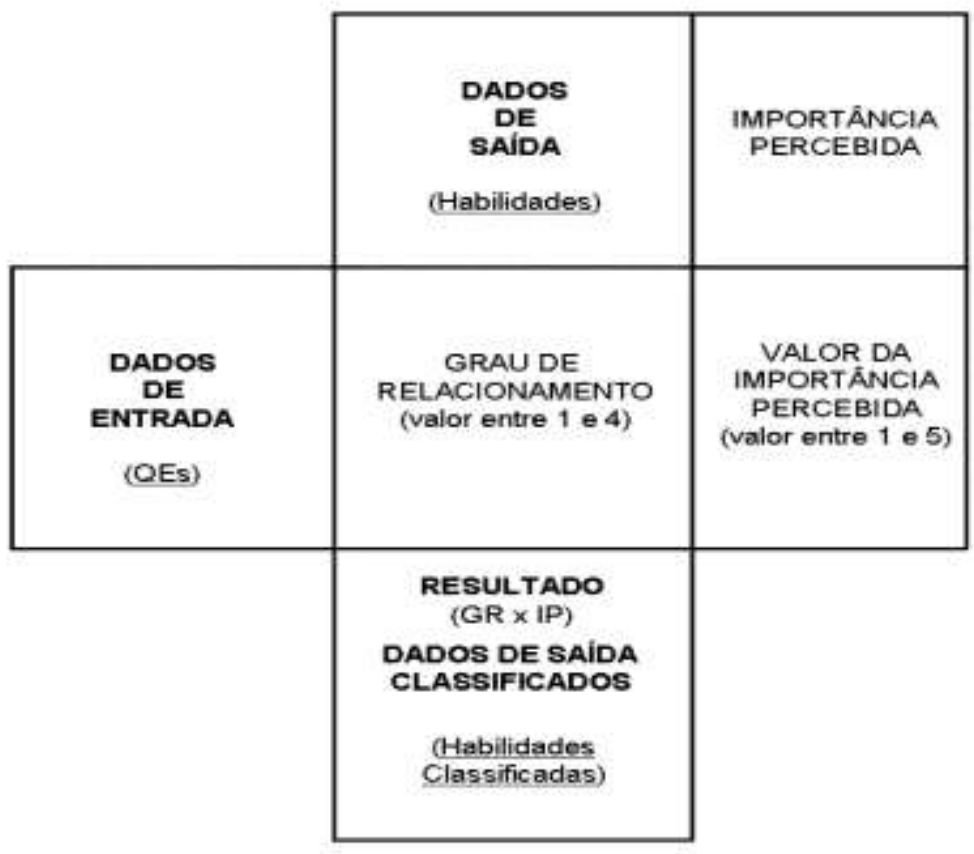

Como pode ser visto, os dados de entrada, relativos as Qualidade Exigidas (QE), são dispostos na primeira coluna. Na primeira linha da matriz são dispostos os 
dados de saída, as habilidades em manufatura. A coluna da direita apresenta os pesos ou a Importância Percebida (IP) para cada Qualidade. Dessa forma, pode-se relacionar cada Qualidade Exigida (dados de entrada) com cada Habilidade em Manufatura (dados de saída), considerando o Grau de Relacionamento (GR) entre eles e o nível de Importância Percebida (IP) para cada Qualidade (Ver Equação 1). Para o GR, são utilizados os seguintes valores numéricos: 1, 2, 3 e 4, conforme as relações mostradas e explicadas através dos exemplos abaixo:

1) Relação Negativa Forte /direta: quando duas variáveis têm uma relação prejudicial entre si, as quais são diretamente impactantes. Exemplo: "confiável - dado de entrada" e "customização - dado de saída". O produto feito de forma customizada para o cliente tem mais probabilidade de apresentar erros de montagem do que uma extensa linha de montagem que segue o mesmo padrão para vários veículos, afetando negativamente e diretamente a confiabilidade do produto.

2) Relação Negativa Fraca /indireta: quando duas variáveis têm uma relação prejudicial entre si, porém, através do impacto de uma variável intermediária. Exemplo: "lucratividade - dado de entrada" e "customização - dado de saída". A customização atrai $\mathrm{o}$ consumidor, em função de 0 produto ser personalizado para ele, porém, não a ponto deste pagar mais pelo produto. Como um produto personalizado tem um custo produtivo maior, isso impacta negativamente nos lucros.

3) Relação Positiva Fraca /indireta: quando duas variáveis têm uma relação contributiva entre si, porém, através do impacto de uma variável intermediária. Exemplo: "crescimento - dado de entrada" e "confiabilidade de entrega - dado de saída". O crescimento é relacionado ao aumento das vendas, a qual aumenta quando a confiabilidade de entrega está boa.

4) Relação Positiva Forte /direta : quando duas variáveis têm uma relação contributiva entre si, as quais são diretamente impactantes. Exemplo: relação entre "qualidade - dado de entrada" e "confiabilidade de entrega - dado de saída". Uma boa qualidade do produto impacta em garantir a sua entrega

Revista Produção Online, Florianópolis, SC, v.13, n. 3, p. 945-973, jul./set. 2013. 
para o consumidor no tempo estipulado ou vice-versa.

Enfim, uma vez preenchido o interior da planilha, verifica-se qual é o valor atribuído para essa Habilidade por meio da somatória dos pontos obtidos segundo a Eq. 1, que multiplica o GR pelo IP.

$$
\sum_{i=1}^{n} G R(i) x I P(i)
$$

Eq. 1

Onde:

$\mathrm{GR}=$ Grau de relacionamento entre $\mathrm{QEs}$ e habilidades ;

IP = Importância Percebida para cada Qualidade;

$\mathrm{n}=$ número total de linhas da matriz.

A segunda casa, denominada por Matriz Dimensões, utiliza como dados de entrada as informações obtidas na etapa anterior, as habilidades, com seus níveis de relevância para a empresa, resultantes da primeira casa. Estas são relacionadas com as dimensões da flexibilidade, similar à primeira casa. $\mathrm{O}$ que altera é que, a partir da segunda casa, é utilizado o conceito de "Importância Relativa", ao invés de "Importância Percebida", avaliada pela empresa, uma vez que as habilidades provenientes da primeira casa já entram na segunda casa com seus índices de importância previamente calculados através da Equação 1. O mesmo ocorre para as outras duas matrizes.

O terceiro passo é relacionar as dimensões com os elementos da flexibilidade. Dessa forma, ao final da terceira matriz, denominada por Matriz Elementos, é possível conhecer quais elementos da flexibilidade têm mais impacto na satisfação das demandas do mercado e percepção dos clientes, alinhados à estratégia da empresa.

$\mathrm{Na}$ quarta matriz, denominada por Matriz Recursos, os elementos da flexibilidade são relacionados com os recursos provedores da flexibilidade. Acreditase que esse estágio seja suficiente para esclarecer "o que adquirir prioritariamente e quando implantar esses recursos", em função da sua relevância para o mercado e 
para a estratégia da empresa.

A Figura 3 - Exemplo simplificado de desdobramento estratégico da flexibilidadesimula uma aplicação do referido método. A simulação parte do princípio que uma das necessidades da empresa é se aproximar dos clientes. Dessa forma, a habilidade "customização" (personalização de produtos) é uma das habilidades que poderia ser fortemente relacionada com essa necessidade na primeira casa. Na segunda casa, a habilidade "customização" poderia ser relacionada com a dimensão "modificação". $\mathrm{Na}$ terceira casa, a dimensão "modificação" poderia ser relacionada com os elementos "variedade e mobilidade". Finalmente, na quarta e última casa, os elementos "variedade e mobilidade" poderiam ser relacionados com a "flexibilidade de mão de obra, capaz de realizar tarefas complexas e polivalentes", orientando quanto a operacionalização da flexibilidade para tornar real a personalização demandada pelo cliente.

Figura 3 - Exemplo simplificado de desdobramento estratégico da flexibilidade.

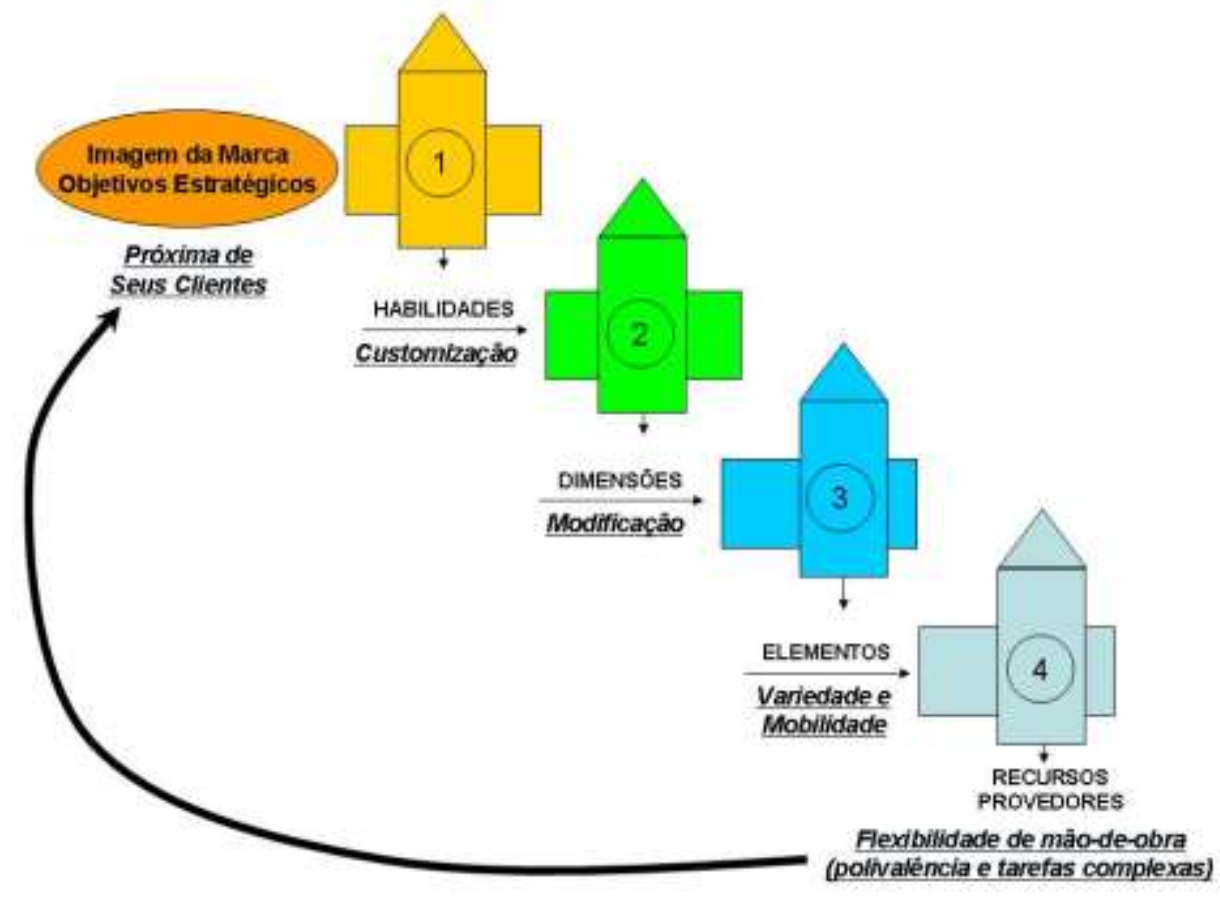

Para avaliar o potencial do método proposto, o mesmo foi aplicado em campo industrial, conforme descrição apresentada no item quatro. 


\section{ESTUDO EM CAMPO: APLICAÇÃO E AVALIAÇÃO DO MÉTODO DEF}

O campo é composto pelo setor de funilaria de uma empresa automobilística de veículos leves, localizada no Sul do Brasil. Esse campo foi escolhido por ser o ambiente de trabalho de um dos autores e por possuir demanda por flexibilidade, além de características apresentadas nesse trabalho como robôs, mão de obra qualificada, arranjo físico misto, entre outros.

A linha de produção automotiva, escolhida para a aplicação do método proposto, tem capacidade para fabricar 45 veículos por hora, totalizando aproximadamente 900 veículos de passeio por dia, distribuídos em 9 modelos diferentes. Apesar da alta variedade e média homogeneidade, existem restrições no processo produtivo que fazem com que o "mix de fabricação" seja rígido, ou seja, a proporção entre os modelos produzidos é quase constante, independente das variações de preferência do consumidor. As produções horárias, em número de veículos previstos por modelo, e seus limites máximos de produção estão descritos no Erro! Fonte de referência não encontrada..

Quadro 2 - Capacidade de produção horária.

\begin{tabular}{|c|c|c|}
\hline Modelo & $\begin{array}{c}\text { Numero previsto } \\
\text { para a fabricação } \\
\text { dos modelos/h }\end{array}$ & $\begin{array}{c}\text { Capacidade máxima de } \\
\text { produção por modelo/h }\end{array}$ \\
\hline A & 3 & 12 \\
B & 2 & 18 \\
C & 1 & 18 \\
D & 2 & 18 \\
E & 3 & 12 \\
F & 2 & 6 \\
G & 24 & 29 \\
H & 6 & 16 \\
I & 2 & 2 \\
\hline TOTAL & 45 & 131 \\
\hline
\end{tabular}

Ao analisar o Quadro 2, constata-se que, apesar da empresa possuir uma capacidade de produção prevista de 45 veículos por hora, considerando uma variedade de 9 modelos, essa capacidade está condicionada às restrições de variedade. Nenhum modelo de veículo seria capaz de atingir a totalidade da capacidade de produção prevista pela fábrica, de 45 veículos por hora. A 
capacidade máxima que mais se aproximaria desse numero seria as 29 unidades do modelo G, considerando a capacidade máxima se houvesse apenas esse modelo na linha. Ou seja, caso o mercado consumidor desejasse comprar 45 unidades por hora do modelo G, a fábrica precisaria utilizar estratégias que impactariam em custos de fabricação, como "horas extras", por exemplo. Entretanto, a prática mostra que, ao enfrentar situações como essa, a empresa prefere perder o mercado para a concorrência, do que alterar muito o seu processo produtivo. Além do mercado, acaba perdendo, também, lucratividade em função do aumento dos custos fixos, uma vez que parte das instalações e da mão de obra acabam sendo subutilizadas.

A Figura 4 apresenta um arranjo físico simplificado da linha de produção analisada nesse estudo.

Figura 4 - Arranjo físico fabril dos 9 modelos de carro (A, B, C, D, E, F, G, H, I).

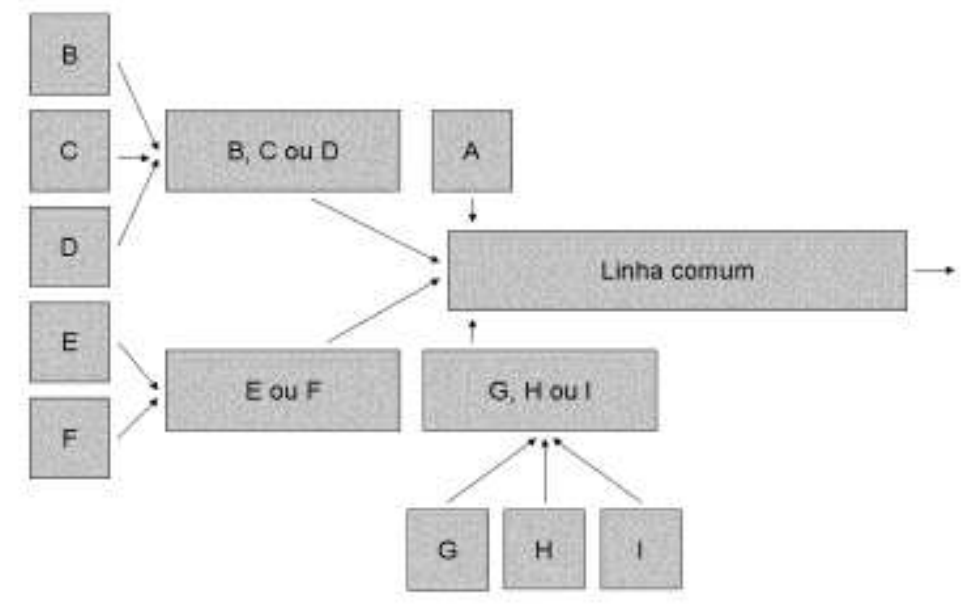

A linha comum, compartilhada por todos os modelos, é a fase com maior nível de automação, referente à aproximadamente 90\%. Em segundo lugar, a linha comum de produção dos modelos B, C ou D são um pouco mais automatizadas que as demais linhas. Isso demonstra que, apesar de todos os modelos finalizarem na mesma linha, a sua fabricação inicial não tem o mesmo ritmo, o que tende a restringir a velocidade da fabricação final, acelerando alguns modelos e atrasando outros que poderiam ser mais ágeis. Ou seja, a linha acaba sendo regulada em função dos modelos mais lentos, resultando em um número menor de veículos do 
que a capacidade da linha.

\subsection{Aplicação do método DEF na linha de fabricação estudada}

A coleta de dados realizada nesse processo produtivo constituiu-se de três fases. Na primeira buscou-se identificar quais requisitos a empresa deveria endereçar, a fim de satisfazer seus clientes e sua estratégia empresarial. Para identificar esses requisitos, foram consultados alguns documentos da empresa estudada. Ao conciliar os objetivos estratégicos com a imagem de marca pretendida pela empresa, frente aos consumidores, foram selecionados seis requisitos que compõe as Qualidades Exigidas (QE), que são os dados de entrada da primeira casa. São eles: três a nível estratégico (crescimento, lucratividade e qualidade) e três relacionados com a identidade da marca (próxima, entusiasta e confiável).

$\mathrm{Na}$ segunda fase aplicou-se um questionário cujo objetivo era que os informantes atribuíssem pesos para as QEs previamente identificadas (Ver Quadro $3)$.

Quadro 3 - Questionário aplicado para a coleta das qualidades exigidas.

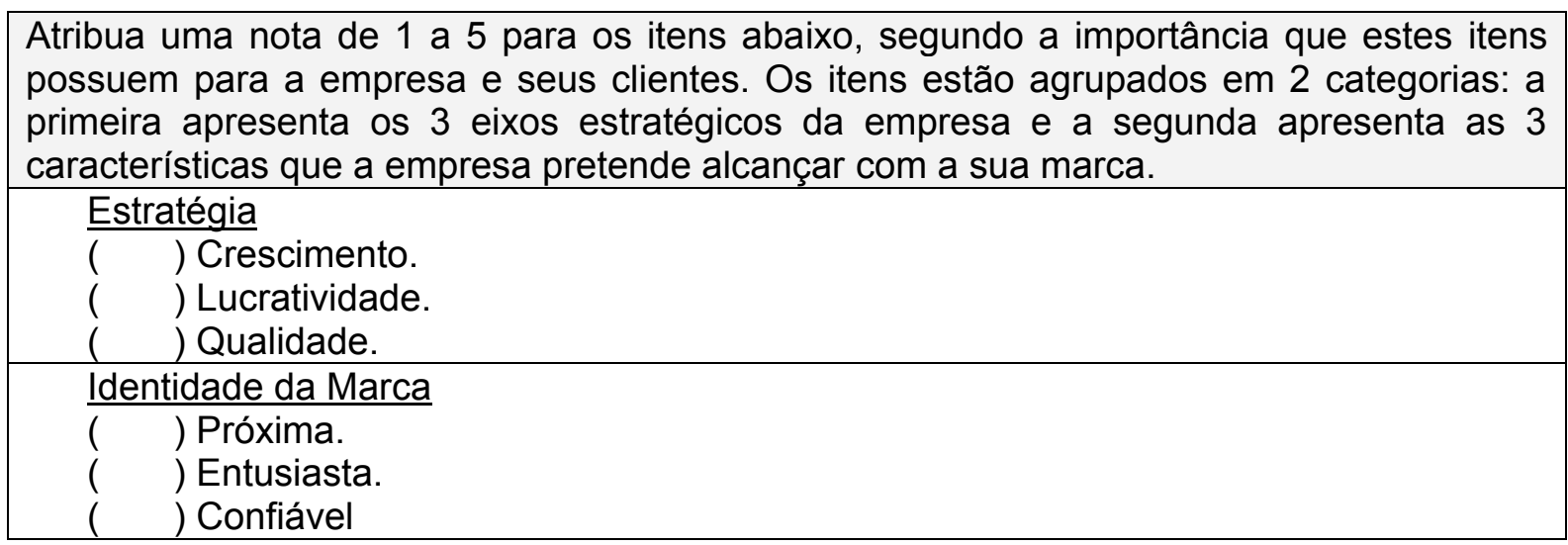

O questionário foi repassado para oito supervisores de produção e engenharia, os quais responderam separadamente. Desses, oito eram supervisores de produção de funilaria, pintura e montagem (dois de cada uma das áreas) e dois eram supervisores de engenharia de processo, sendo um de funilaria e outro de montagem. Apenas para auxiliar no preenchimento da primeira casa, julgou-se 
necessário interagir com pessoas envolvidas com a produção dos veículos. Para as demais avaliações (demais casas), os dados foram desdobrados pelos autores, baseando-se nas revisões bibliográficas e experiência de um dos autores, que atuava como supervisor da produção dos veículos em questão.

Sendo assim, originou-se o Erro! Fonte de referência não encontrada., o qual apresenta na primeira coluna as duas classes de objetivos relacionados à estratégia e à identidade da marca da empresa. Na segunda coluna são listadas as Qualidades Exigidas. As colunas identificadas como “ $a, b, c, d$, e” apresentam as notas atribuídas pelos entrevistados para representar o nível de importância das QEs de 1 a 5 . Finalmente, a coluna IP apresenta um número inteiro, resultado da média aritmética simples dos valores atribuídos para " $a, b, c, d$, e", que representa o peso ou a importância de cada Qualidade Exigida, segundo a percepção dos entrevistados, denominado por Importância Percebida.

Quadro 4 - Qualidades Exigidas e Importância Percebida.

\begin{tabular}{|c|l|c|c|c|c|c|c|}
\cline { 2 - 8 } \multicolumn{2}{c|}{} & $\mathrm{a}$ & $\mathrm{b}$ & $\mathrm{c}$ & $\mathrm{d}$ & $\mathrm{e}$ & $\mathrm{IP}$ \\
\hline \multirow{4}{*}{ Estratégia } & Crescimento & 5 & 3 & 4 & 3 & 4 & 4 \\
\cline { 2 - 9 } & Lucratividade & 3 & 3 & 5 & 3 & 4 & 4 \\
\cline { 2 - 9 } & Qualidade & 5 & 5 & 4 & 3 & 5 & 4 \\
\hline \multirow{3}{*}{$\begin{array}{c}\text { Identidade da } \\
\text { Marca }\end{array}$} & Próxima & 5 & 5 & 5 & 5 & 5 & 5 \\
\cline { 2 - 9 } & Entusiasta & 5 & 3 & 5 & 4 & 3 & 4 \\
\cline { 2 - 8 } & Confiável & 5 & 5 & 4 & 5 & 5 & 5 \\
\hline
\end{tabular}

Constata-se que as QEs "Próxima" e "Confiável" são mais significativas que as demais, na percepção dos entrevistados. Com as Qualidades Exigidas e as suas respectivas Importâncias Percebidas, inicia-se a correlação das QEs com as Habilidades em Manufatura.

A Matriz de Habilidades, apresentada no Quadro 5, relaciona as Qualidades Exigidas com as Habilidades em manufatura. As informações de entrada (QE) são dispostas na primeira coluna. Na parte superior da matriz são dispostas as habilidades em manufatura, conforme a classificação apresentada no Quadro 1: 
confiabilidade de entrega, customização, disponibilidade, inovação tecnológica, lucratividade, preço baixo, produtividade, qualidade e velocidade de entrega. $\mathrm{Na}$ coluna da direita consta a Importância Percebida.

Quadro 5 - Matriz de Habilidades.

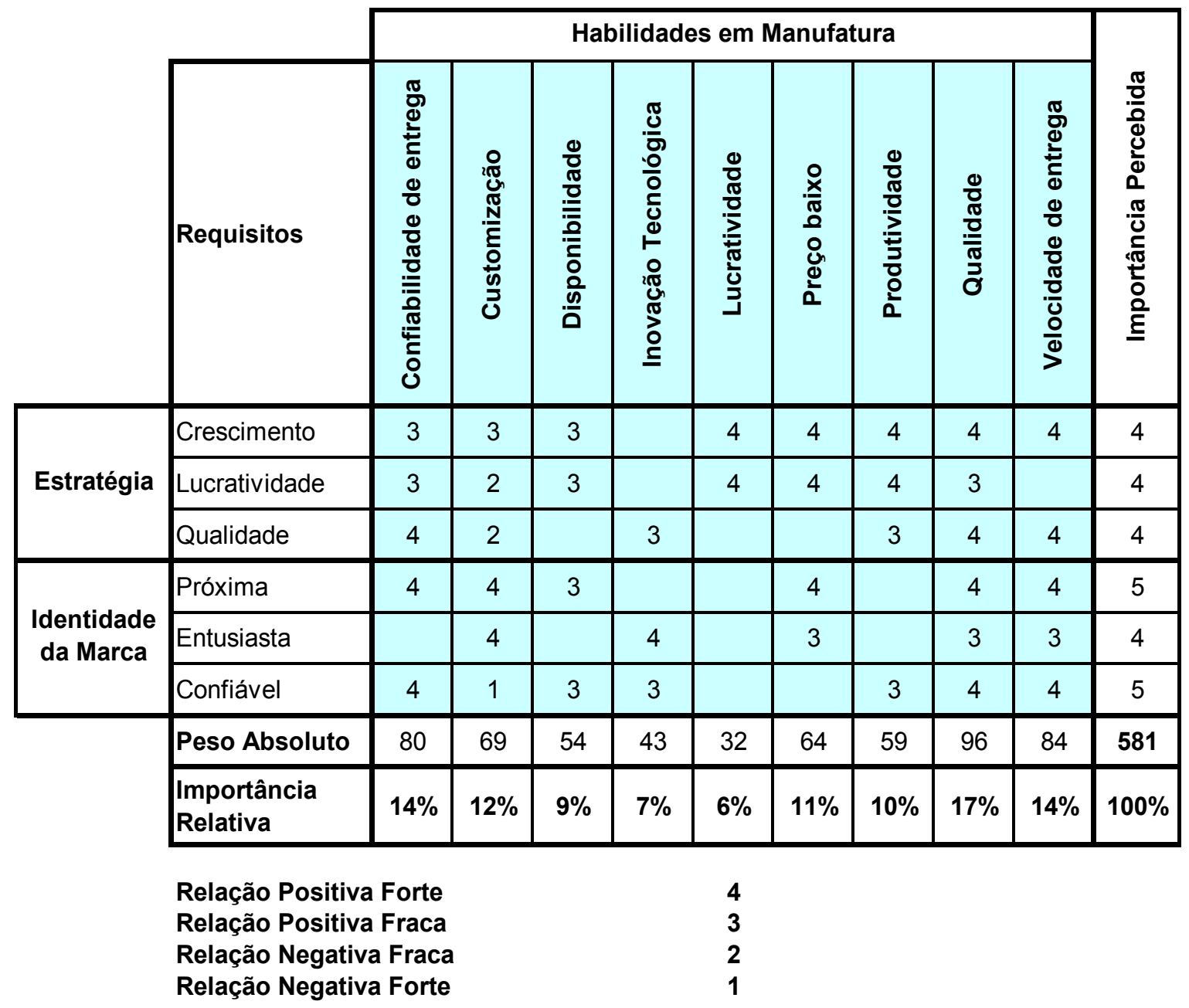

Conforme o Quadro 5, as habilidades em manufatura foram relacionadas com cada qualidade exigida, resultando em diferentes níveis de relação. A relevância das habilidades é resultante da soma dos pontos obtidos segundo a Equação 1, ou seja, a habilidade mais relevante é a Qualidade, que obteve um valor de 96 pontos, resultante da somatória dos valores mostrados na sua coluna, multiplicados cada um pela sua IP correspondente. Nesse caso, as de maior pontuação são as mais importantes para o atendimento das qualidades exigidas. São elas: "qualidade, velocidade de entrega e confiabilidade de entrega" respectivamente. 
Os percentuais foram resultantes de uma regra de três simples, onde 581 pontos representa $100 \%$ da somatória dos itens relacionadas à habilidade. Sendo assim, 96 pontos atribuídos à habilidade - qualidade significa $17 \%$ desse total e, assim, sucessivamente.

A segunda Matriz do método proposto utiliza como dados de entrada os dados de saída da casa anterior, ou seja, das habilidades em manufatura, classificadas segundo os seus pesos relativos. Os dados de entrada são dispostos na primeira coluna, conforme apresentado no Quadro 6. Nas demais colunas são dispostas as características identificadas como dimensões da flexibilidade, segundo o referencial teórico (Quadro 1): flexibilidade de mix, de novos produtos, de volume e de entrega. O objetivo é relacionar cada habilidade em manufatura com cada dimensão da flexibilidade a fim de identificar quais dimensões são mais significativas em relação às qualidades exigidas.

O Quadro 6 utiliza a Importância Relativa da Casa anterior (última linha), onde "Qualidade" representou 17\%, por exemplo, e insere esses valores na última coluna desse quadro, representando a coluna da Importância. A Importância Relativa apresentada na última linha é resultante da mesma equação aplicada na primeira casa. Se considerarmos a somatória da multiplicação de cada coluna pelo seu correspondente na coluna da Importância (ultima coluna), conforme Equação 1, obtém-se os seguintes valores: 164, 150, 180 e 199, o que totaliza 693 pontos. Se 693 significa 100\%, 164 pontos significa $23 \%$ dessa amostra e assim por diante.

Analisando o Erro! Fonte de referência não encontrada. é possível avaliar quais dimensões são mais significativas para as QEs endereçadas pela empresa, destacando-se as flexibilidades de entrega e de volume. É importante salientar a utilização do telhado a partir dessa segunda casa. O telhado é um diagrama de relacionamento que permite a análise qualitativa da relação entre características do mesmo nível. A análise do telhado é referente ao fato de uma dimensão desejada contribuir (+) ou prejudicar (-) outra dimensão desejada. Por exemplo: na Matriz Dimensões constata-se que a dimensão "flexibilidade de volume" tende a ser auxiliada pela "flexibilidade de mix", uma vez que com uma maior disponibilidade de produtos possíveis de serem fabricados, existe mais facilidade para variar os 
volumes desejados. Sendo assim, o cruzamento dessas variáveis apresenta um sinal positivo. Em contra partida, quanto maior a heterogeneidade de um sistema produtivo, maior o potencial em perder uniformidade, portanto, no cruzamento desses dois itens aparece um sinal negativo. A mesma idéia é aplicada às demais casas apresentadas na sequência.

\begin{tabular}{|c|c|c|c|c|c|}
\hline \multirow{2}{*}{\multicolumn{6}{|c|}{ Quadro 6 - Matriz Dimensões }} \\
\hline & & & & & \\
\hline HABILIDADES & 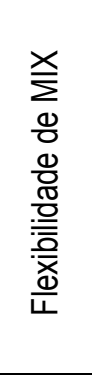 & 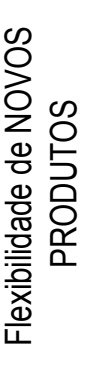 & 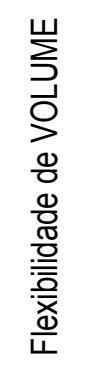 & 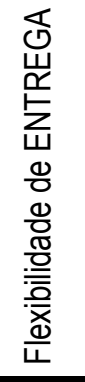 & 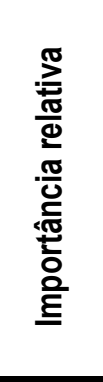 \\
\hline Confiabilidade de entrega & & & & 4 & $14 \%$ \\
\hline Customização & 4 & 4 & 3 & & $12 \%$ \\
\hline Disponibilidade & & 3 & 4 & 4 & $9 \%$ \\
\hline Inovação Tecnológica & & 3 & & & $7 \%$ \\
\hline Lucratividade & 2 & & 4 & & $6 \%$ \\
\hline Preço baixo & 2 & & 4 & & $11 \%$ \\
\hline Produtividade & 2 & 2 & 4 & & $10 \%$ \\
\hline Qualidade & 2 & 2 & & 3 & $17 \%$ \\
\hline Velocidade de entrega & 2 & & & 4 & $14 \%$ \\
\hline Importância Relativa & $23 \%$ & $22 \%$ & $26 \%$ & $29 \%$ & $100 \%$ \\
\hline
\end{tabular}

Relação Positiva Forte

Relação Positiva Fraca

Relação Negativa Fraca

Relação Negativa Forte

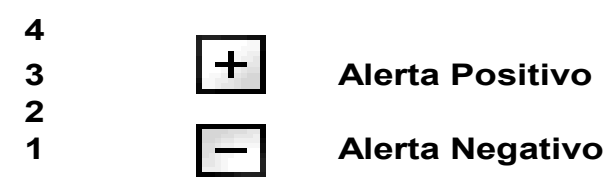

Revista Produção Online, Florianópolis, SC, v.13, n. 3, p. 945-973, jul./set. 2013. 
A terceira casa ou matriz elementos relaciona as dimensões com os elementos da flexibilidade, ressaltando aqueles que devem ser endereçados pela empresa. Os elementos da flexibilidade analisados são: Variedade, Heterogeneidade, Mobilidade e Uniformidade, conforme descritos no Quadro 1. As relações são apresentadas no Quadro , seguindo o mesmo raciocínio do Quadro 6. Nesse quadro é possível constatar que os elementos da flexibilidade mais significativos são uniformidade e variedade, respectivamente.

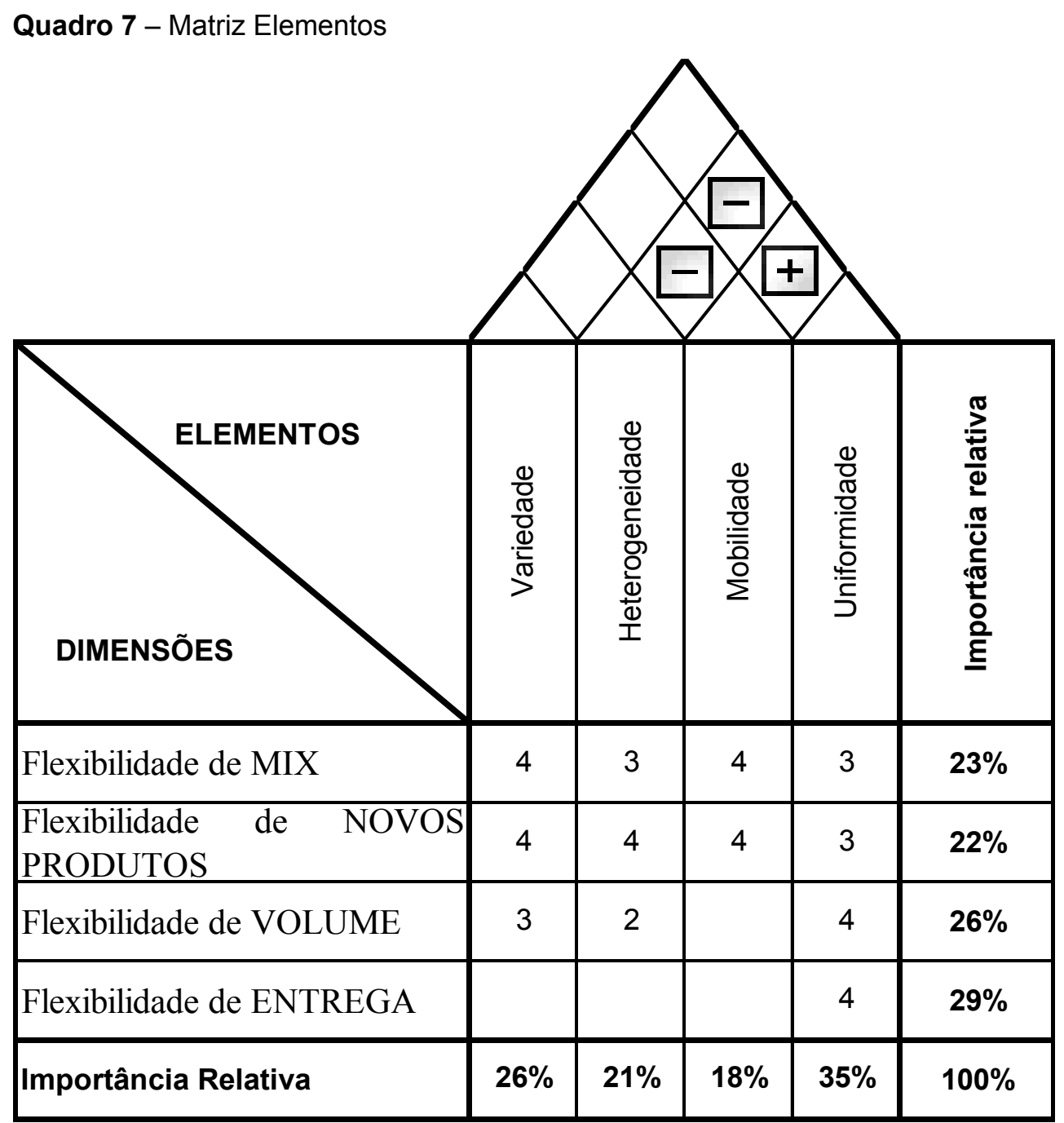

Relação Positiva Forte

Relação Positiva Fraca

Relação Negativa Fraca

Relação Negativa Forte

4

3

2

$+\quad$ Alerta Positivo

1

Alerta Negativo

Revista Produção Online, Florianópolis, SC, v.13, n. 3, p. 945-973, jul./set. 2013. 
A quarta casa ou matriz de recursos provedores permite chegar aos principais recursos provedores da flexibilidade almejada, partindo dos elementos da flexibilidade. Para essa análise são listados os recursos disponíveis ou de fácil aquisição, utilizados ou não pela empresa em questão. A finalidade é identificar quais recursos deveriam ser priorizados pela empresa, a fim de que seu processo de manufatura possa atender às qualidades exigidas, identificadas no início dessa aplicação.

Os recursos provedores da flexibilidade, mostrados no Quadro 1, foram reavaliados pelos autores, considerando, além da experiência dos mesmos, as teorias revisadas nesse trabalho. Sendo assim, os recursos provedores da flexibilidade, escolhidos para compor a quarta matriz, são os seguintes, desdobrados em quatro categorias:

- Flexibilidade de Máquina: Robôs, Controladores Lógico-programáveis, Transportadores dedicados e Transportadores não dedicados;

- Flexibilidade de Mão de obra: Tempo de função, Personalidade, Foco em qualidade, Poli-valência (foco em flexibilidade de tarefa), Foco em custo, Foco em tempo, Responsabilidade compartilhada, Trabalho com Automação e Complexidade do trabalho;

- Flexibilidade de Rota: Arranjo físico posicional, Arranjo físico por processo, Arranjo físico celular e Arranjo físico por produto;

- Flexibilidade de Gestão: Produção em lotes, Reescalonamento, Planejamento e controle da produção e Previsibilidade de produção.

Vale salientar que, tanto a proposição das qualidades exigidas, quanto dos recursos provedores, depende da experiência dos engenheiros de processo envolvidos na aplicação do método. Quanto maior o conhecimento daqueles que o aplicam, no que se refere à empresa, ao mercado e ao processo fabril, mais eficaz torna-se o método. Essa eficácia se refere ao atendimento dos clientes, em consonância com a estratégia da empresa, através do ajuste de recursos que venham a promover a flexibilidade demandada.

A relação entre os elementos e os recursos provedores é apresentada na 
Matriz Elementos,

Quadro . Em função do tamanho dessa casa, os dados que a compõem não podem ser visualizados com nitidez, entretanto, o Quadro 9, mostrado na sequência, apresenta todos os recursos por ordem de importância, resultantes dessa matriz.

\section{Quadro 8 - Matriz Recursos Provedores.}

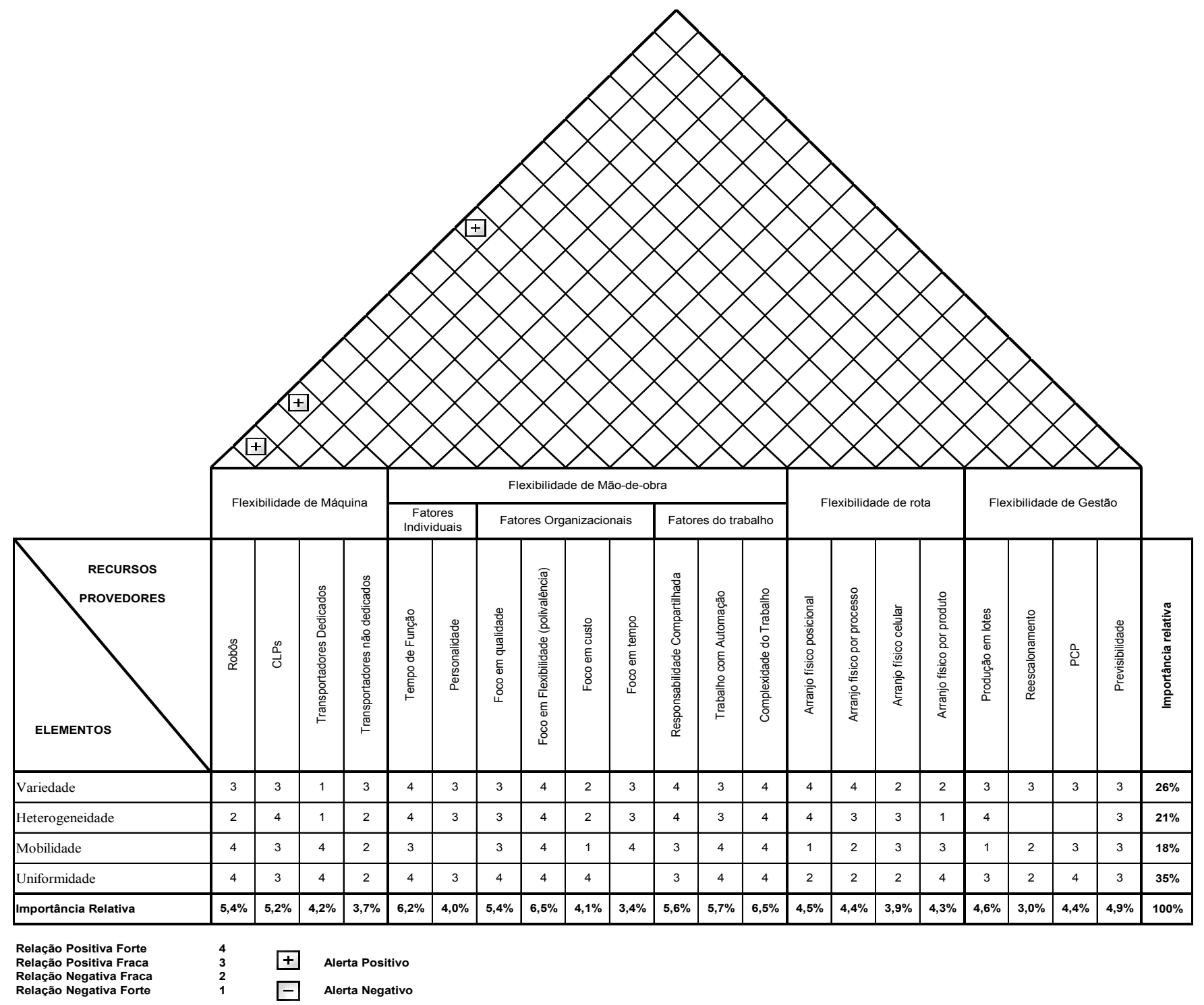

Após a aplicação da quarta casa do método DEF, utilizando-se do mesmo procedimento aplicado nas duas etapas anteriores, os recursos provedores da flexibilidade obtiveram uma classificação que explicita o seu nível de relevância (do

Revista Produção Online, Florianópolis, SC, v.13, n. 3, p. 945-973, jul./set. 2013. 
mais ao menos relevante) (Ver Quadro 9).

Quadro 9 - Nível de importância relativa entre os provedores da flexibilidade

\begin{tabular}{|ll|}
\hline Recursos Provedores da Flexibilidade \\
\hline $6,49 \%$ & Complexidade do Trabalho \\
$6,49 \%$ & Foco em Flexibilidade (poli-valência dos funcionários) \\
$6,20 \%$ & Tempo de Função \\
\hline $5,73 \%$ & Grau de Automação \\
$5,62 \%$ & Responsabilidade Compartilhada \\
$5,44 \%$ & Foco em qualidade \\
$5,40 \%$ & Robôs \\
\hline $5,21 \%$ & CLPs \\
$4,87 \%$ & Previsibilidade fabril \\
$4,62 \%$ & Produção em lotes \\
$4,47 \%$ & Arranjo físico posicional \\
$4,43 \%$ & PCP \\
$4,42 \%$ & Arranjo físico por processo \\
$4,35 \%$ & Arranjo físico por produto \\
$4,22 \%$ & Transportadores Dedicados \\
$4,10 \%$ & Foco em custo \\
$3,99 \%$ & Personalidade \\
$3,88 \%$ & Arranjo físico celular \\
\hline$\underline{3,66 \%}$ & Transportadores não dedicados \\
$3,44 \%$ & Foco em tempo \\
$2,99 \%$ & Reescalonamento \\
\hline
\end{tabular}

Constata-se no Quadro 9 que a "complexidade do trabalho" é o recurso provedor da flexibilidade mais relevante, além de "Foco em Flexibilidade (polivalência dos funcionários)" e "Tempo de Função". Ou seja, fica claro que seria importante a empresa focar na simplificação da tarefa a ser executada pelos funcionários, além de priorizar funcionários experientes e polivalentes. Por outro lado, constata-se que, em função da estratégia da empresa (que visa Crescimento, Lucratividade e Qualidade) e da identidade almejada para a marca do produto (Próxima, Entusiasta e Confiável), os últimos itens dessa lista pouco contribuiriam para operacionalizar a flexibilidade, visando contribuir com essas metas.

Apesar de muitos empresários buscarem a automação de seus processos produtivos, contata-se que o recurso "Grau de Automação" não foi o item mais relevante. Isso se justifica como algo já conhecido daqueles que analisam a questão da flexibilidade versus automação. Conforme Slack et al. (2002), quanto maior o nível de automação, menos flexibilidade se constata em um processo produtivo. Aliás, conforme apresentado no Quadro 1 nos itens sublinhados no Quadro 9, 
constata-se que os recursos provedores relacionados às máquinas são a minoria nesse contexto.

\section{CONCLUSÕES}

Um método para orientar a escolha de recursos provedores da flexibilidade, segundo a demanda do mercado consumidor e dos objetivos estratégicos de uma empresa de manufatura, foi proposto nesse artigo.

A avaliação é baseada em uma taxonomia sugerida para desdobrar a flexibilidade até o nível dos recursos capazes de promover a flexibilidade almejada, considerando quatro níveis de desdobramento: habilidades, dimensões, elementos e recursos provedores da flexibilidade.

O método foi estruturado e testado em uma empresa fabricante de veículos leves, o qual mostrou bom desempenho. Os resultados obtidos com o estudo explicitaram, entre outros fatores, que a empresa vem empregando alto índice de automação, o que vem gerando problemas de restrições de mix. Infere-se que esse problema poderia ser minimizado através da simplificação das tarefas envolvidas na fabricação dos 9 modelos de carros da linha estudada, assim como, com a contratação de funcionários mais experientes e polivalentes dos que os atuantes no processo. Essa conclusão foi resultante da aplicação do método que mostrou que esses itens seriam os de maior relevância para prover a flexibilidade almejada por esta empresa no momento do estudo, em 2007.

Analisando os impactos do estudo no processo estudado, após 2007, pode-se dizer que: a linha de produção foi simplificada, não apenas pelas sugestões resultantes do trabalho, mas por mudanças estratégicas da empresa. A empresa decidiu não reinvestir nos modelos antigos (modelos $B, C$ e D) e preferiu transferir parte dos modelos produzidos para a sua planta situada na Argentina (modelos A e E) (Ver Figura 4). Na planta de fabricação automotiva estudada, atualmente existe um novo modelo $(\mathrm{J})$, cujo processo é mais simples dos que os anteriormente estudados nesse trabalho. Sendo assim, os modelos existentes atualmente são os seguintes: F, G, H, I e J, sendo apenas o F de uma geração mais antiga, o qual não 
compartilha a mesma plataforma dos demais. Todos os outros têm muitos componentes em comum, de forma que o processo de produção é muito similar, repetitivo e otimizado. Ou seja, hoje o processo fabril está mais em conformidade com o "Recurso Provedor da Flexibilidade" prioritário, segundo as resultantes do método aplicado, mostrando redução da complexidade do trabalho.

Sugere-se para trabalhos futuros que um estudo detalhado seja feito em um processo fabril que possa ser alterado após a análise com o método, visando quantificar, através de indicadores previamente selecionados, as melhorias em termos de flexibilidade e alinhamento com os objetivos da empresa.

Enfim, acredita-se que este método possa orientar aqueles que necessitem identificar os principais recursos provedores da flexibilidade para o seu caso específico, obtendo um alinhamento adequado com o mercado consumidor e com as estratégias do negócio.

\footnotetext{
${ }^{1}$ Trabalho resultante de dissertação de mestrado (UTFPR - Campus Curitiba).
}

\section{REFERÊNCIAS}

AKAO, Y. Introdução ao desdobramento da qualidade: manual de aplicação do desdobramento da função qualidade. Belo Horizonte: Fundação Cristiano Ottoni, 1990.

BEAMON, B. M. Measuring supply chain performance. International Journal of Operations \& Production Management, v. 19, n. 3, p. 275-292, 1999.

BORDOLOI, S. K. et al. Flexibility, adaptability, and efficiency in manufacturing systems. Production and Operations Management, v. 8, n. 2, p. 133-149, 1999.

BOYLE, T. A.; SCHERRER-RATHJE, M. An empirical examination of the best practices to ensure manufacturing flexibility - lean alignment. Journal of Manufacturing Technology Management, v. 20, n.3, p. 348-366, 2009.

BROWNE, J. et al. Classification of flexible manufacturing systems. The FMS Magazine, v. 2, n.1, p. 114-117, 1984.

CONCEIÇÃO, S. V. et al. Desenvolvimento e implementação de uma metodologia para troca rápida de ferramentas em ambientes de manufatura contratada. Revista Gestão da Produção, v. 16, n.3, p.357-369, 2009. 
COUSENS, A. et al. A process for managing manufacturing flexibility. International Journal of Operations \& Production Management, v. 29, n.4, p. 357-385, 2009.

D' SOUZA, D. E.; WILLIAMS, F. P. Toward a taxonomy of manufacturing flexibility

Dimensions. Journal of Operations Management, v. 18, n.5, p. 577-593, 2000.

HYUN, J. K.; AHN, B. H. A unifying framework for manufacturing flexibility.

Manufacturing Review, v. 5, n.4, p. 251-260, 1992.

KARA, S.; KAYIS, B. Manufacturing flexibility and variability: an overview. Journal of Manufacturing Technology Management, v. 15, n. 6, p. 466-478, 2004.

KARUPPAN, C. M. Strategies to foster labor flexibility. International Journal of Productivity and Performance Management, v. 53, n. 6, p. 532-547, 2004.

KOSTE, L. L.; MALHOTRA, M. K. A theoretical framework for analyzing the dimensions of manufacturing flexibility. Journal of Operations Management, v. 18, n.1, p. 75-93, 1999.

KOSTE, L. L.; MALHOTRA, M. K. Trade-offs among the elements of flexibility: a comparison from the automotive industry. The International Journal of Management Science, v.28, n.6, p. 693-710, 2000.

KOSTE, L. L. et al. Measuring dimensions of manufacturing flexibility. Journal of Operations Management, v. 22, n. 2, p. 171-196, 2004.

MARILYN T. L.; OLGA M. K. Reconciling the resource-based and competitive positioning perspectives on manufacturing flexibility. Journal of Manufacturing Technology Management, v. 22, n.2, p. 189-203, 2011.

NAKAMOTO, F. Y. et al. Geração automática da solução de controle para alocação de recursos utilizando redes de Petri. Revista Produção, v. 19, n.1, p. 8-26, 2009.

NARAIN, R. et al. The strategic implications of flexibility in manufacturing systems. International Journal of Agile Management Systems, v. 2, n. 3, p. 202-213, 2000.

OKE, A. A framework for analyzing manufacturing flexibility. International Journal of Operations \& Production Management, v. 25, n. 10, p. 973-996, 2005.

OLHAGER, J.; WEST M. B. The house of flexibility: using the QFD approach to deploy manufacturing flexibility. International Journal of Operations \& Production Management, v. 22, n. 1, p. 50-79, 2002.

RODRIGUES, A. G.; GOMEZ, A. T. Tratamento de um problema de escalonamento considerando datas de entrega, turnos de produção e trocas de ferramentas via Busca Tabu. Revista Produção online, v. 18, n. 1, p. 64-75, 2008. 
SCHEWCHUK, J. P.; MOODIE, C. L. Definition and classification of manufacturing flexibility types and measures. The International Journal of Flexible

Manufacturing Systems, v. 10, n.4, p. 325-349, 1998.

SETHI, A. K.; SETHI S. P. Flexibility in manufacturing: a survey. The International Journal of Flexible Manufacturing Systems, v.2, n.4, p. 289-328, 1990.

SLACK, N. Flexibility as a manufacturing objective. International. Journal of Operations \& Production Management, v. 3, n. 3, p. 4-13, 1983.

SLACK, N. The flexibility of manufacturing systems. International Journal of Operations \& Production Management, v. 7, n. 4, p. 35-45, 1987.

SLACK, N. et al. Administração da Produção. São Paulo: Ed. Atlas S. A., 2002.

SUAREZ, F. F. et al. An empirical study of manufacturing flexibility in printed circuit board assembly. Operations Research, v. 44, n. 1, p.223-240, 1996.

UPTON, D. M. Flexibility as process mobility: the management of plant capabilities for quick response manufacturing. Journal of Operations Management, v. 12, n. 34, p.205-224, 1994.

YAZICI, H. J. Influence of flexibilities on manufacturing cells for faster delivery using simulation. Journal of Manufacturing Technology Management, v. 16, n. 8, p.825841, 2005.

ZHANG, Q. et al. Manufacturing flexibility: defining and analyzing relationships among competence, capability, and customer satisfaction. Journal of Operations Management, v. 21, n. 2, p. 173-191, 2003.

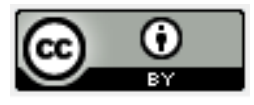

Artigo recebido em 08/03/2012 e aceito para publicação em 24/07/2013 